\title{
Impact of dietary L-arginine supply during early gestation on myofiber development in newborn pigs exposed to intra-uterine crowding
}

\author{
Johannes Gulmann Madsen ${ }^{1,2}$, Camilo Pardo ${ }^{1,2}$, Michael Kreuzer² and Giuseppe Bee ${ }^{1 *}$ (1)
}

\begin{abstract}
Background: Intra-uterine crowding (IUC) observed in hyperprolific sows impairs myofiber hyperplasia and overall fetal growth. Arginine supplementation (ARG) in gestation diets has been shown to positively affect litter and muscle development. The study objective was to assess whether the effect of ARG on offspring characteristics, with special emphasis on myofiber hyperplasia, differs under IUC conditions from these responses, because in that situation growth retardation is particularly prevalent due to reduced fetal nutrient supply. Unilateral oviduct ligation (OL) was used as a model for an uncrowded and hyperprolificacy (IN) as a model for a crowded intra-uterine environment.
\end{abstract}

Methods: Five OL and five IN sows were fed a diet supplemented daily with either $43 \mathrm{~g}$ L-alanine (Ctrl) or $25 \mathrm{~g}$ L-arginine from d 14 to 28 of gestation in a cross-over design (two periods: $5^{\text {th }}$ and $6^{\text {th }}$ parity). At farrowing, two male and two female offspring, respectively, with a low and intermediate birth weight (BtW) were selected. After euthanization, the Semitendinosus muscle (STM) was removed and weighed, and the light and dark portions $\left(S_{T M}\right.$ and STM $\left._{l}\right)$ were prepared for myofiber histochemistry using ATPase staining and the entire STM for gene expression analysis of myogenesis-related genes using RT-qPCR. In addition, various organs were removed and weighed. Data were analyzed using the MIXED model in SYSTAT.

Results: No effect of either IUC or dietary treatment was found in litter characteristics. Offspring of ARG sows displayed a greater muscle area in STM $(P<0.01)$ as a result of the greater myofiber hyperplasia $(P<0.01)$. The increase was more distinct in the $\operatorname{STM}_{\mathrm{l}}(P<0.05)$ than in the $\operatorname{STM}_{d}(P=0.131)$. Offspring of OL sows were heavier at birth $(P<0.01)$, had a heavier STM $(P<0.05)$, liver $(P<0.01)$ and kidney $(P<0.05)$, but when expressed relative to birth weight, these differences were absent. In addition, IUC had an effect $(P<0.05)$ on the expression of one of the myogenesis-related genes investigated.

Conclusions: Independent from the extent of IUC, ARG improved BtW, muscle and organ weights and myofiber hyperplasia in offspring.

Keywords: Dietary supplement, Early gestation, Intra-uterine growth restriction, Myofiber hyperplasia, Neonate, Sow prolificacy

\footnotetext{
* Correspondence: giuseppe.bee@agroscope.admin.ch

${ }^{1}$ Agroscope Posieux, la tioleyre 4, 1725 Posieux, Switzerland

Full list of author information is available at the end of the article
} 


\section{Background}

In the last decade, the selection for high prolificacy in modern sow herds has led to a marked increase in litter sizes. One consistent outcome of this strategy was the increasing number of less vital and less mature low birth weight $(\mathrm{L}-\mathrm{BtW})$ piglets $[1,2]$. In these piglets, prenatal muscle development is impaired [3, 4] as evidenced by the lower myofiber number and the greater number of myofibers still expressing the fetal myosin heavy chain isoform at birth [4]. Compared with their heavier siblings, the lower prenatal myofiber hyperplasia observed in underprivileged piglets has negative consequences on postnatal growth efficiency [5] and lean meat deposition rate $[6,7]$.

The pig muscle develops in a biphasic manner [8] (Fig. 1). In a first wave from d 35-55 of gestation, an initial population of myoblasts fuse to form primary (P) myofibers. From d 55-90 of gestation, these primary myofibers serve as scaffold for the fusion of a second larger population of myoblasts, the so-called secondary (S) myofibers $[9,10]$. As opposed to $S$ myofiber development where crowding of the uterus at early gestation appears to be a compromising factor [11], P myofiber number is assumed to be a fixed genetic component, and its development is assumed to be unaffected by conditions occurring in utero [12]. However, a recent study showed that hyperplasia of P myofibers was greater in the Semitendinosus muscle (STM) of 75-day-old fetuses originating from sows fed a diet supplemented with L-arginine from d 14-28 of gestation [13]. Because supplementation of L-arginine occurred before the start of P myofiber formation, the authors hypothesized that this effect was an indirect effect. Earlier supplementation of L-arginine from d 0-14 is not advisable because of its detrimental effect on embryonic survival, which is likely due to reduced progesterone secretion [14]. Arginine is a common substrate for nitric oxide and polyamine synthesis [15], both of which are key regulators of angiogenesis and placental growth [16]. Therefore, an increased dietary arginine supply might improve the fetal nutrient supply [17] and ultimately promote myofiber hyperplasia. This mode of action could be interesting especially for offspring from prolific sows suffering from intra-uterine growth retardation (IUGR) due to a crowded intra-uterine environment which impairs placental and, consequently, fetal development.

Based on the aforementioned association between dietary arginine supply, the extent of placental vascularization, the fetal nutrient supply and muscle development, it was hypothesized that supplementing L-arginine to an early gestational diet of the dams would promote hyperplasia leading to an increased number of myofibers in their offspring at birth. A second hypothesis tested the theory of whether L-arginine would be especially efficient in piglets suffering from IUGR. Two sow models were established for the present study, one 'non-crowded' and the other 'relatively crowded' simulated by intact (IN) prolific sows. The non-crowded intra-uterine environment was mimicked by using unilaterally oviduct ligated (OL) sows. In these sows, oocytes ovulated from the ovary ipsilateral to the ligated oviduct are prevented from being fertilized and entering the uterus. Therefore, the number of embryos and the extent of crowding in utero is markedly reduced in OL compared with IN sows $[13,17]$.

\section{Methods}

Animals and dietary treatments

The study was conducted as a $2 \times 2$ crossover design (two periods for each sow in their $5^{\text {th }}$ and $6^{\text {th }}$ parity). It involved five OL sows originating from a previous experiment of Pardo et al. [18] and five prolific IN sows.

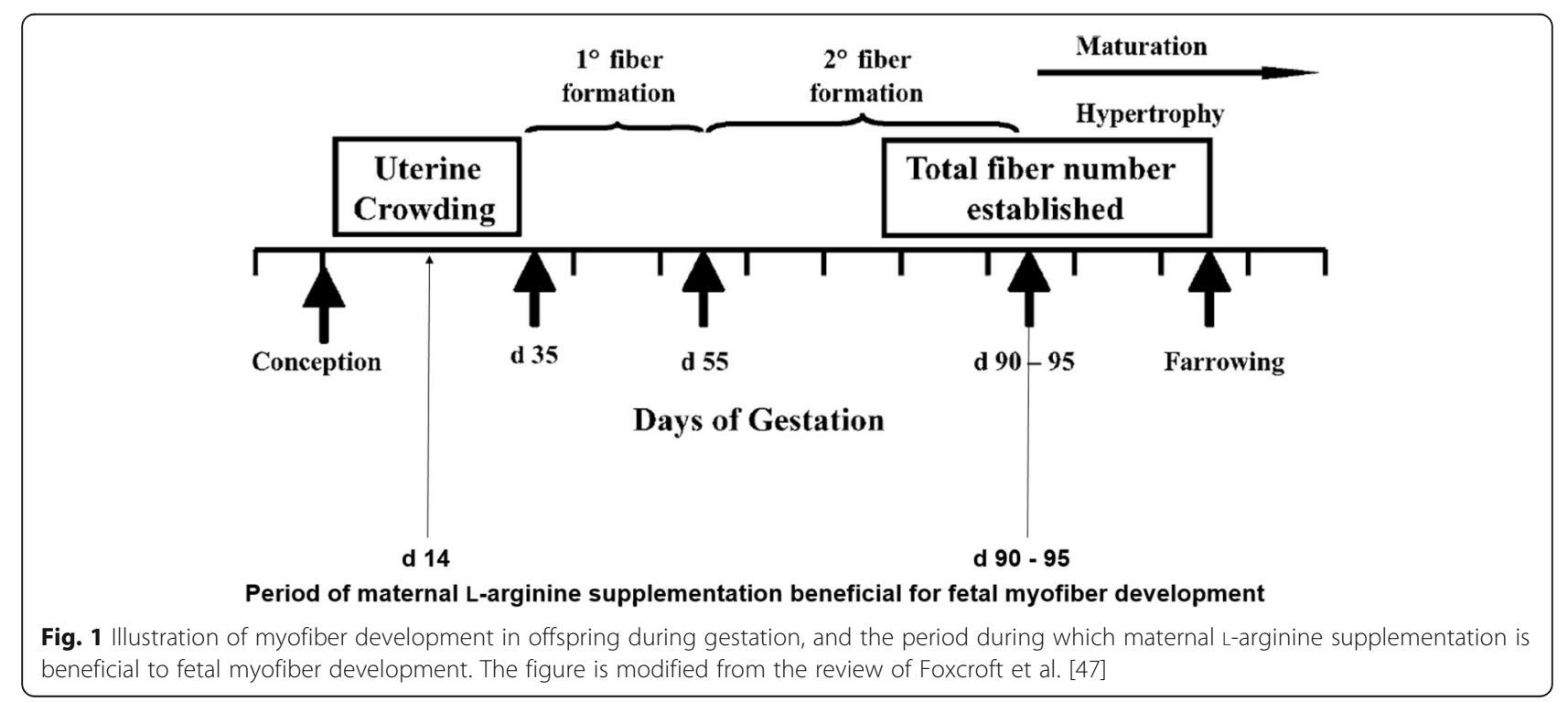


The five IN sows were siblings to the five OL sows. Except from d 14 to 28 of gestation, the sows were reared from mating to farrowing with other multiparous sows in group pens equipped with an automatic feeder (Compident, Model 2000, Schauer, Prambachkirchen, Austria) and were offered $2.8 \mathrm{~kg}$ of a standard gestation diet daily (Table 1). From d 14 to 28 of gestation, the sows were kept in individual pens. They were randomly allotted to receive daily either $25 \mathrm{~g}$ L-arginine $\mathrm{HCl}$ (ARG), an amount based on the previous findings of Bérard and

Table 1 Ingredients and calculated nutrient composition of the gestation diet $^{1}$

\begin{tabular}{|c|c|}
\hline Item & Gestation diet \\
\hline \multicolumn{2}{|l|}{ Ingredients, $\%$ as-fed } \\
\hline Barley & 25.0 \\
\hline Oat & 20.0 \\
\hline Dried sugar beet pulp & 14.3 \\
\hline Wheat bran & 10.0 \\
\hline Soybean meal & 5.7 \\
\hline Dried apple pomace & 5.6 \\
\hline Dried whole maize plant & 5.0 \\
\hline Animal fat (70\% lard and $30 \%$ tallow) & 3.0 \\
\hline Linseed meal & 2.0 \\
\hline Potato protein & 2.0 \\
\hline Rapeseed meal & 2.0 \\
\hline Molasses & 2.0 \\
\hline Dicalcium phosphate & 1.16 \\
\hline Calcium carbonate & 0.75 \\
\hline Sodium chloride & 0.56 \\
\hline Pellan ${ }^{2}$ & 0.40 \\
\hline Vitamin-mineral premix ${ }^{3}$ & 0.40 \\
\hline \multicolumn{2}{|l|}{ Amino acids ${ }^{4}, \%$} \\
\hline L-lysine $\mathrm{HCl}$ & 0.08 \\
\hline L-threonine & 0.06 \\
\hline \multicolumn{2}{|l|}{ Calculated composition, \% DM } \\
\hline Dry matter, \% of wet weight & 88.35 \\
\hline Total ash & 7.20 \\
\hline Ether extract & 6.80 \\
\hline Crude protein & 15.10 \\
\hline Digestible energy, MJ/kg DM & 13.70 \\
\hline
\end{tabular}

${ }^{1}$ In the ARG group, the pellets were top dressed with $25 \mathrm{~g}$ L-arginine $\mathrm{HCl}$ / (sow.d), and in the Ctrl group, the pellets were top dressed with 43 $\mathrm{g}$ L-alanine/(sow.d)

${ }^{2}$ Binder that aids in pellet formation (Mikro-Technik, GmbH \& Co. KG, Germany)

${ }^{3}$ Contains: vitamin A: 2,000,000 U/kg; vitamin $D_{3}: 200,000 \mathrm{U} / \mathrm{kg}$; vitamin E: 10 g/kg; l: 137.4 mg/kg; Mn: 5 g/kg; Cu: 1.75 g/kg; Zn: 1.4 g/kg; Se: 50 mg/kg ${ }^{4}$ Calculated amino acid composition, $\mathrm{g} / \mathrm{kg} \mathrm{DM}$ : alanine: 6.42 ; arginine: 8.51 aspartate plus asparagine: 12.70 ; cystine: 3.15 ; glutamate plus glutamine: 27.50; glycine: 6.54 ; histidine: 3.42 ; isoleucine: 5.74 ; leucine: 10.72 ; lysine: 7.90 ; methionine: 2.46 ; phenylalanine: 7.00 ; proline: 9.59 ; serine: 6.73 ; threonine: 6.30; tryptophan: 1.83 ; tyrosine: 5.03 ; valine: 7.38
Bee [13], or $43 \mathrm{~g} \mathrm{~L}$-alanine (Ctrl) both as top dressing for $14 \mathrm{~d}$. Alanine was used to compensate for the increased amount of nitrogen in the ARG treatment making the two dietary treatments isonitrogenous.

\section{Data and tissue sample collection at farrowing}

At the end of farrowing, litter characteristics including the number of piglets born alive and stillborn and their individual body weights were recorded. At the day of farrowing, two female and two male piglets per sow per parity were intentionally sacrificed, one with the lowest BtW (L: average \pm standard deviation (SD): $1.24 \pm 0.30$ $\mathrm{kg}$ ) and one with intermediate BtW (M: average \pm STD: $1.49 \pm 0.26 \mathrm{~kg}$ ). Thus, the aim was to include a total of 80 piglets in the study. However, due to unforeseen events at farrowing, the final number was only 70 piglets, which were balanced accordingly between the extent of crowding (38 vs. 32, IN and OL), dietary treatment (36 vs. 34, Ctrl and ARG), BtW (33 vs. 37, L and M), sex (34 vs. 36, male and female), and parity (33 vs. $37,5^{\text {th }}$ and $6^{\text {th }}$ ). Pigs with a $\mathrm{BtW}$ of $<800 \mathrm{~g}$ were considered runts and were not included in the study. The selected piglets were anaesthetized using an isoflurane-oxygen mixture [4\% vol/vol] and subsequently euthanized by exsanguination. Subsequently, the complete Semitendinosus muscle (STM) and Psoas major muscle (PM) were removed and weighed. The STM was split into the light and dark portions $\left(\mathrm{STM}_{1}\right.$ and $\mathrm{STM}_{\mathrm{d}}$ ). A section from each portion was removed from the middle of the muscle, snap-frozen in 2-methylbutane cooled in liquid nitrogen and subsequently stored at $-80^{\circ} \mathrm{C}$ until histochemical analysis was performed. Subsequently, spleen, kidneys, heart, lungs, liver and brain were removed and weighed.

\section{Histochemical analysis of the semitendinosus muscle}

The P and S myofibers were differentiated histochemically using the protocol described previously by Bérard et al. [4]. Briefly, $10 \mu \mathrm{m}$ cross-sections of the $\mathrm{STM}_{\mathrm{d}}$ and $\mathrm{STM}_{\mathrm{l}}$ were prepared and stained for the determination of myofibrillar ATPase activity after acid $(\mathrm{pH} 4.5)$ or alkaline $(\mathrm{pH}$ 10.3) preincubation. In the $\mathrm{STM}_{\mathrm{d}}$, the $\mathrm{P}$ myofibers stain dark, and the $S$ myofibers light, using the acid preincubation condition, whereas the opposite occurs after basic preincubation. This differentiation was possible in the $\mathrm{STM}_{\mathrm{d}}$, whereas, in accordance with observations of the study by Bérard et al. [4], P and S myofibers could not be differentiated in the $\mathrm{STM}_{1}$ of newborn pigs using this mATPase histochemistry assay. A sectional cut of the entire muscle area was stained using anti-slow myosin heavy chain monoclonal antibody (Novocastra lyophilized mouse monoclonal antibody myosin heavy chain (NCL-MHCs) diluted 1:20 in ultrapure water; Novocastra, Newcastle, UK). This allowed a clear determination of the $\mathrm{STM}_{\mathrm{d}}$ and $\mathrm{STM}_{\mathrm{l}}$ cross-sectional areas. 
The number of $\mathrm{P}$ myofibers were determined in the mATPase sections after acid pre-incubation, where 750 $\mathrm{P}$ myofibers were counted in an area of $0.89 \mathrm{~mm}^{2}$. The number of $\mathrm{P}$ myofibers, counted in the selected area, and the cross-sectional area of the $\mathrm{STM}_{\mathrm{d}}$ was used to estimate the total number of $\mathrm{P}$ myofibers. The number of $\mathrm{S}$ myofibers was determined in mATPase sections after alkaline preincubation. Four images were taken and analyzed using the analySIS software 5.0 (Soft Imagine System, Olympus Soft Imaging Solutions $\mathrm{GmbH}$, Münster, Germany). At least $33 \mathrm{P}$ myofibers were selected, and all the surrounding $\mathrm{S}$ myofibers were counted (> $1000 \mathrm{~S}$ myofibers). This permitted estimating the total $\mathrm{S}$ myofiber number as well as calculating the S:P myofiber ratio. The total number of myofibers (TNF) in the $\mathrm{STM}_{\mathrm{d}}$ was calculated from the respective estimated total number of $\mathrm{P}$ and $\mathrm{S}$ myofibers. In the $\mathrm{STM}_{\mathrm{l}}$, the number of myofibers was determined in mATPase sections after acid preincubation, where $>3000$ myofibers were counted in an area of 1.47 $\mathrm{mm}^{2}$. The number of counted myofibers, the according measurement area $\left(1.47 \mathrm{~mm}^{2}\right)$ and the cross-sectional area of the $\mathrm{STM}_{1}$ were used to estimate TNF.

\section{Gene expression analysis of myogensis-related genes in the Semitendinosus muscle}

Of the 70 piglets, samples from five individuals (1 LBtW and $1 \mathrm{M}$-BtW male from ARG-IN sows, $2 \mathrm{~L}-\mathrm{BtW}$ females from ALA-IN sows and 1 L-BtW male from ALA-IN sow) were of too poor quality for analysis of gene expression, thus in a total of 65 piglets, total mRNA was extracted from $50 \mathrm{mg}$ STM by the phenol-chloroform extraction protocol involving homogenization with $\mathrm{IKA}^{\odot}$ T10 basic Ultra-Turrax ${ }^{\ominus}$ (IKA, Staufen, Germany) and phase separation with peqGOLD TriFast $^{\mathrm{TM}}$ (Peqlab, Erlangen, Germany). Centrifugation steps were carried out at $4{ }^{\circ} \mathrm{C}$ and $12,000 \times g$. Tissue was cut into pieces of $5 \mathrm{mg}$ and homogenized for $20 \mathrm{~s}$ in $1 \mathrm{~mL}$ of TriFast TM reagent. After $5 \mathrm{~min}$ of incubation at room temperature, $200 \mu \mathrm{L}$ of chloroform was added, shaken for $15 \mathrm{~s}$ and incubated at room temperature for $10 \mathrm{~min}$. Subsequently, phases were separated by centrifugation, and the supernatant containing the mRNA was carefully removed and mixed with $500 \mu \mathrm{L}$ of isopropanol, precooled at $4{ }^{\circ} \mathrm{C}$. Following a $15 \mathrm{~min}$ incubation on ice, the tube was centrifuged, the supernatant discarded and the pellet washed in precooled $\left(4^{\circ} \mathrm{C}\right) 500 \mu \mathrm{L}$ of ethanol. After a last centrifugation step at 7,500 $\times g$ for 8 min, the ethanol was discarded and the pellet was dried at room temperature. Finally, the mRNA was resuspended in $100 \mu \mathrm{L}$ nuclease-free water under agitation at $55^{\circ} \mathrm{C}$. Quality and concentrations of sample mRNA were measured with a NanoDrop ${ }^{\oplus}$ ND-1000 (Thermo Scientific, Waltham, Massachusetts, USA). Primers for both target and reference genes are listed in Table 2. All primers were designed with Primer3 v.4.0.0 (http://primer3.wi.mit.edu/), tested for dimerization with OligoAnalyzer ${ }^{\oplus}$ v.3.1 (Integrated DNA Technologies, Coralville, Iowa, USA), and subsequently purchased in SePOP quality dissolved in water (Eurogentec, Seraing, Belgium). Reverse transcription of complementary DNA (cDNA) was performed with ImProm-II ${ }^{\mathrm{TM}}$ Reverse Transcription System (Promega, Dübendorf, Switzerland). First, random hexamer primers were annealed to the mRNA $(5 \mu \mathrm{L}$ of DNAse-treated mRNA with $1 \mu \mathrm{L}$ of random hexamers, incubation at $70{ }^{\circ} \mathrm{C}$ for $5 \mathrm{~min}$. The mRNA was then subjected to the reverse transcription (using 20 $\mu \mathrm{L}$ reaction solutions with $4 \mu \mathrm{L}$ of $5 \times$ buffer, $2.4 \mu \mathrm{L}$ of 25 $\mathrm{mmol} / \mathrm{L} \mathrm{MgCl}_{2}, 1 \mu \mathrm{L}$ of $10 \mathrm{mmol} / \mathrm{L}$ dNTPs, $1 \mu \mathrm{L}$ of reverse transcriptase and $5.6 \mu \mathrm{L}$ nuclease-free water, according to manufacturer's protocol). Finally, the freshly synthesized cDNA was diluted $12.5 \times$ with nuclease-free water and stored at $4{ }^{\circ} \mathrm{C}$ until further use. Real time-qPCR was carried in $20 \mu \mathrm{L}$ reaction solutions consisting of $10 \mu \mathrm{L}$ of $2 \times$ KAPA $^{\mathrm{TM}} \mathrm{SYBR}^{\oplus}$ FAST Master Mix (Kapa Biosystems, Woburn, Massachusetts, USA), $4.2 \mu \mathrm{L}$ of water, $0.4 \mu \mathrm{L}$ $10 \mu \mathrm{mol} / \mathrm{L}$ of both forward and reverse primers and $5 \mu \mathrm{L}$ of cDNA sample. Amplification was carried out in a Rotor-Gene 6000 (Corbett Life Sciences, Sydney, Australia) under the following conditions: A 3 min hold at $95{ }^{\circ} \mathrm{C}$ followed by 40 cycles with $10 \mathrm{~s}$ of denaturation at $95^{\circ} \mathrm{C}, 10 \mathrm{~s}$ of annealing at $60{ }^{\circ} \mathrm{C}$ : Insulin-like growth factor 2 (IGF2), Insulin-like growth factor binding protein 5 (IGFBP5), Myogenic factor 6 (MYF6), Myogenic differentiation 1 (MYOD), Protein kinase, AMP-activated, alpha 2 catalytic subunit (PRKAA2), TATA box binding protein $(T B P), 20 \mathrm{~s}$ at $60{ }^{\circ} \mathrm{C}$ : Myogenin (MYOG) or $20 \mathrm{~s}$ at $62{ }^{\circ} \mathrm{C}$ : Myostatin (MSTN), Myogenic factor 5 (MYF5), Ribosomal protein L4 (RPL4) and $20 \mathrm{~s}$ extension time at $72{ }^{\circ} \mathrm{C}$ with the last $4 \mathrm{~s}$ being used for fluorescence measurements. The cycling was followed by acquisition of a melt curve (from $72{ }^{\circ} \mathrm{C}$ to $95{ }^{\circ} \mathrm{C}$, in increments of $1{ }^{\circ} \mathrm{C}$ each 5 s) to control the specificity of the PCR product. Owing to the large number of samples, it was decided to amplify all samples for a given gene in one run. Two technical replicates were performed in two further runs (rather than measuring technical replicates in the same run). To reduce inter-run variation, the reactions in all three runs were prepared with the same mastermix.

The modified formula by Livak and Schmittgen [19] suitable for multiple reference genes was applied to gene expression data, and the relative quantification was performed with the qBase+ software (Biogazelle NV, Zwijnaarde, Belgium) [20].

\section{Statistical analysis}

Data were analyzed using the MIXED procedure of SYSTAT version 13 (Systat Software, San Jose, CA). All data were tested for normality of residuals. For litter traits, data were analyzed including IUC and dietary treatment $(\mathrm{DIET}), \mathrm{IUC} \times \mathrm{DIET}$ interaction, parity, and 
Table 2 Forward and reverse primers of myogenesis-related genes and reference genes

\begin{tabular}{|c|c|c|c|}
\hline & Accession no. & Forward primer (from 5' to $3^{\prime}$ ) & Reverse primer (from $5^{\prime}$ to $3^{\prime}$ ) \\
\hline \multicolumn{4}{|l|}{ Gene } \\
\hline IGF2 & NM_213883 & TGGCATCGTGGAAGAGTG & AGGTGTCATAGCGGAAGAAC \\
\hline IGFBP5 & U41340 & GTGTACCTGCCCAACTGTGA & AAGCTGTGGCACTGGAAGTC \\
\hline MSTN & NM_214435 & CCCGTCAAGACTCCTACAACA & CACATCAATGCTCTGCCAA \\
\hline MYF5 & Y17154 & CCTGAATGCAACAGCCCT & CGGAGTTGCTGATCCGAT \\
\hline MYF6 & NM_001244672 & CGCCATCAACTACATCGAGAGGT & ATCACGAGCCCCCTGGAAT \\
\hline MYOD1 & NM_001002824 & GGTGACTCAGACGCATCCA & ATAGGTGCCGTCGTAGCAGT \\
\hline MYOG & NM_001012406 & CAACCAGGAGGAGCGAGAC & GAGGTGAGGGAGTGCAGATT \\
\hline PRKAA2 & NM_214266 & CCCCTGAAACGAGCAACTATC & CACACTTCTITCACAGCCTCAT \\
\hline \multicolumn{4}{|c|}{ Reference genes } \\
\hline RPL4 & DQ845176 & CAAGAGTAACTACAACCTTC & GAACTCTACGATGAATCTTC \\
\hline TBP & DQ178129 & GATGGACGTTCGGTTTAGG & AGCAGCACAGTACGAGCAA \\
\hline
\end{tabular}

${ }^{1 / G F 2}$ Insulin-like growth factor 2, IGFBP5 Insulin-like growth factor binding protein 5, MSTN Myostatin, MYF5 myogenic factor 5, MYF6 myogenic factor 6, MYOD1 Myogenic differentiation 1, MYOG Myogenin (myogenic factor 4), PRKAA2 Protein kinase AMP-activated, alpha 2 catalytic subunit, RPL4 (LOC100038029) Ribosomal protein L4, TBP TATA box binding protein

boar as fixed effect, offspring as random effect, and sow as the experimental unit. Data on absolute and relative STM and PM weight, absolute and relative organ weight, total area of STM, TNF of STM, P and S number of myofibers, the S:P ratio of $\mathrm{STM}_{d}$, area of $\mathrm{STM}_{\mathrm{d}}, \mathrm{STM}_{\mathrm{l}}$ and gene expression were analyzed including the main factors of IUC, DIET, sex, sow, parity, BtW (nested within sow), IUC $\times \mathrm{D}$ and BtW $\times$ DIET interaction as fixed, and boar as random effect. For all analyses of the piglet data, sow was used as variable in a repeated measurement procedure. Birth weight was nested within sow as birth weight intervals ( $\mathrm{L}$ and $\mathrm{M}$ ) were not unique among sows, leading to the individual piglet being assigned either $\mathrm{L}$ or $\mathrm{M}$ depending on the dam. The final model was determined by performing backward elimination of non-significant three- and two-way interactions. Offspring was used as the observational unit.

Least squares means of the interaction means concerning the main factors IUC and DIET are presented in the result tables. As the effect of sex and BtW was rarely significant, these least square means were only reported in the text when $P<0.05$. The PAIRWISE option using the Tukey adjustment was used to determine differences between interaction effects when two-way interactions occurred. Differences were considered statistically significant at $P<0.05$ and as tendency at $0.05<P<0.10$.

\section{Results}

\section{Sow performance and litter characteristics}

The number of total born and born alive piglets, and the male to female ratio were not different between IN and OL sows and were also not affected by the dietary ARG supply (Table 3). Average litter BtW, average BtW of female and male newborns as well as BtW variability, expressed as standard deviation (SD), also did not differ between IN and OL sows and between the ARG and Ctrl dietary treatments. Regarding stillborns, the five IN sows gave birth to one, two, two, four and five stillborn piglets, respectively, and only one OL sow gave birth to one stillborn piglet. Thus, the number of stillborn piglets were unevenly distributed: $\mathrm{IN}-\mathrm{Ctrl}=7$; IN-ARG $=7$; OL-Ctrl $=1$; OL$\mathrm{ARG}=0$. Due to the greatly unbalanced distribution between experimental treatment groups, statistical analysis of number and $\mathrm{BtW}$ of stillborn piglets was not performed.

\section{Birth weight and absolute and relative muscle and organ weights}

There were no significant effects of sow type and diet type on BtW of total born and born alive piglets (Table 3 ). Birth weight of males born alive from IN sows fed the ARG diet were heavier in tendency than those fed the Ctrl diet, whereas $\mathrm{BtW}$ of males born alive were lighter in tendency when originating from OL sows fed the ARG instead of the Ctrl diet (IUC $\times$ DIET interaction; $P=0.087$ ). The average $\mathrm{BtW}$ of the selected offspring was lower than of the litter average because half of the piglets were of deliberately low BtW (Table 4). The piglets selected from the OL sows compared with those from the IN sows were heavier $(P=0.008)$ at birth, and had greater $(P \leq 0.033)$ STM, PM, liver and kidney weights. The weight of the spleen tended $(P=0.068)$ to be greater in OL compared with IN offspring. When expressed per $100 \mathrm{~g} \mathrm{BtW}$, the relative weights of the muscles and organs did not differ. The selected offspring from ARG compared with Ctrl sows tended $(P<0.10)$ to have greater $\mathrm{BtW}$, absolute STM weight, liver weight and a lower brain:liver weight ratio. Except for the relative heart weight, which was lower $(P=0.030)$ in ARG 
Table 3 Reproductive characteristics of oviduct ligated (OL; non crowded) and intact (IN; relatively crowded) sows fed an unsupplemented (Ctrl) or L-arginine supplemented gestation diet (ARG) from d 14 to 28 of gestation ${ }^{1}$

\begin{tabular}{|c|c|c|c|c|c|c|c|c|}
\hline \multirow[b]{2}{*}{ Item } & \multicolumn{2}{|l|}{ IN } & \multicolumn{2}{|l|}{$\mathrm{OL}$} & \multirow[b]{2}{*}{ SEM } & \multicolumn{3}{|c|}{$P$-value ${ }^{2}$} \\
\hline & $\mathrm{Ctrl}$ & ARG & $\mathrm{Ctrl}$ & $\mathrm{ARG}$ & & IUC & DIET & $\mathrm{IUC} \times \mathrm{DIET}$ \\
\hline Observations & 5 & 5 & 5 & 5 & & & & \\
\hline Total born & 15.5 & 15.3 & 10.5 & 11.9 & 1.71 & 0.255 & 0.722 & 0.657 \\
\hline Born alive & 13.1 & 14.5 & 9.1 & 10.3 & 1.49 & 0.230 & 0.463 & 0.961 \\
\hline Male:female ratio & 0.47 & 0.62 & 0.50 & 0.41 & 0.093 & 0.508 & 0.732 & 0.368 \\
\hline \multicolumn{9}{|l|}{ Birth weight, kg } \\
\hline Total born & 1.22 & 1.48 & 1.57 & 1.51 & 0.068 & 0.278 & 0.214 & 0.126 \\
\hline \multicolumn{9}{|l|}{ Born alive } \\
\hline All & 1.24 & 1.50 & 1.59 & 1.53 & 0.068 & 0.277 & 0.224 & 0.133 \\
\hline Male & 1.31 & 1.46 & 1.74 & 1.63 & 0.079 & 0.224 & 0.511 & 0.087 \\
\hline Female & 1.26 & 1.51 & 1.50 & 1.44 & 0.092 & 0.580 & 0.365 & 0.230 \\
\hline$S D^{c}$ & 0.24 & 0.25 & 0.18 & 0.14 & 0.056 & 0.414 & 0.869 & 0.626 \\
\hline
\end{tabular}

${ }^{1}$ Results are presented as least squares means of interactions between the two main factors extent of intra uterine crowding and dietary treatment and pooled SEM ${ }^{2}$ Probability values for the effects of extent of intra uterine crowding (IUC), dietary treatment (DIET), and interaction IUC $\times$ DIET

${ }^{3}$ Measure for variability in birth weight, expressed as standard deviation (SD).

Table 4 Birth weight, absolute and relative muscle and organ weights and brain:liver weight ratio of offspring born from oviduct ligated (OL; non crowded) and intact (IN; relatively crowded) fed an unsupplemented (Ctrl) or L-arginine supplemented diet (ARG) from d 14 to 28 of gestation ${ }^{1}$

\begin{tabular}{|c|c|c|c|c|c|c|c|c|c|c|}
\hline \multirow[b]{2}{*}{ Item } & \multicolumn{2}{|l|}{ IN } & \multicolumn{2}{|l|}{$\mathrm{OL}$} & \multirow[b]{2}{*}{ SEM } & \multirow[b]{2}{*}{ IUC } & \multicolumn{3}{|c|}{$P$-value ${ }^{2}$} & \multirow[b]{2}{*}{ DIET $\times B+W$} \\
\hline & Ctrl & ARG & Ctrl & ARG & & & DIET & BtW & IUCXDIET & \\
\hline Observations & 19 & 19 & 17 & 15 & & & & & & \\
\hline Birth weight, kg & 1.06 & 1.21 & 1.58 & 1.59 & 0.128 & 0.008 & 0.068 & 0.564 & 0.137 & $<0.001$ \\
\hline \multicolumn{11}{|l|}{ Weights, $g$} \\
\hline Semitendinosus muscle & 2.08 & 2.48 & 3.47 & 3.60 & 0.417 & 0.025 & 0.074 & 0.571 & 0.426 & 0.009 \\
\hline Psoas major muscle & 2.15 & 2.36 & 3.86 & 4.02 & 0.343 & 0.001 & 0.232 & 0.543 & 0.891 & 0.024 \\
\hline Heart & $8.34^{\mathrm{a}}$ & $10.54^{b}$ & $8.35^{\mathrm{ab}}$ & $7.38^{\mathrm{ab}}$ & 1.695 & 0.418 & 0.159 & 0.806 & 0.005 & 0.032 \\
\hline Liver & 20.91 & 27.39 & 45.98 & 47.55 & 5.808 & 0.004 & 0.053 & 0.529 & 0.290 & 0.022 \\
\hline Spleen & 1.05 & 1.00 & 1.45 & 1.50 & 0.164 & 0.063 & 0.938 & 0.918 & 0.537 & 0.052 \\
\hline Lungs & 16.48 & 18.24 & 19.86 & 18.66 & 2.655 & 0.576 & 0.750 & 0.459 & 0.152 & 0.010 \\
\hline Kidneys & 7.68 & 8.93 & 12.77 & 12.73 & 1.516 & 0.033 & 0.301 & 0.771 & 0.322 & 0.022 \\
\hline Brain & 32.22 & 33.01 & 33.85 & 34.32 & 0.781 & 0.235 & 0.119 & 0.621 & 0.699 & 0.031 \\
\hline Brain:liver weight ratio & 1.36 & 1.12 & 0.94 & 0.92 & 0.222 & 0.270 & 0.077 & 0.151 & 0.182 & 0.001 \\
\hline \multicolumn{11}{|l|}{ Weights, g/100 g BtW } \\
\hline Semitendinosus muscle & 2.09 & 2.08 & 2.19 & 2.28 & 0.095 & 0.328 & 0.415 & 0.716 & 0.341 & 0.511 \\
\hline Psoas major muscle & 2.06 & 2.14 & 2.31 & 2.39 & 0.140 & 0.277 & 0.276 & 0.314 & 0.987 & 0.483 \\
\hline Heart & 0.70 & 0.67 & 0.67 & 0.65 & 0.023 & 0.492 & 0.030 & 0.770 & 0.720 & 0.338 \\
\hline Liver & 2.21 & 2.47 & 2.78 & 2.77 & 0.179 & 0.128 & 0.192 & 0.629 & 0.142 & 0.343 \\
\hline Spleen & $0.10^{b}$ & $0.09^{a}$ & $0.09^{a b}$ & $0.09^{a b}$ & 0.006 & 0.665 & 0.176 & 0.734 & 0.018 & 0.556 \\
\hline Lung & 1.47 & 1.39 & 1.31 & 1.27 & 0.109 & 0.363 & 0.250 & 0.235 & 0.762 & 0.655 \\
\hline Kidney & 0.74 & 0.72 & 0.80 & 0.82 & 0.043 & 0.270 & 0.764 & 0.613 & 0.396 & 0.627 \\
\hline Brain & 2.87 & 2.53 & 2.47 & 2.50 & 0.323 & 0.616 & 0.169 & 0.204 & 0.114 & $<0.001$ \\
\hline
\end{tabular}

${ }^{1}$ Results are presented as least squares means of interactions between the two main factors extent of intra uterine crowding and dietary treatment and pooled SEM ${ }^{2}$ Probability values for the effects of extent of intra uterine crowding (IUC), dietary treatment (DIET), birth weight $(B t W)$, and interactions IUC $\times$ DIET and DIET $\times$ BtW

a,b Within a row for the main factor treatment, least squares means without a common superscript differ $(P<0.05)$ 
than Ctrl offspring, muscle and organ weights relative to BtW were not affected by the dietary treatment of the sow. There was an IUC $\times$ DIET interaction $(P=0.005)$ indicating that absolute heart and relative spleen weight were greater and lower, respectively, in IN-ARG compared with IN-Ctrl piglets. Birth weight had no effect on either absolute or relative STM, PM, organ weights and brain:liver weight ratio. There were a number of significant $(P<0.05)$ diet $\times$ BtW interactions. Compared with L-piglets, M-piglets born from sows fed the ARG, but not the Ctrl diet, had heavier STM (L-ARG $=2.679$ vs. $\mathrm{M}-\mathrm{ARG}=3.401 \mathrm{~g}), \mathrm{PM}(\mathrm{L}-\mathrm{ARG}=2.840$ vs. $\mathrm{M}-\mathrm{ARG}=$ $3.547 \mathrm{~g})$, hearts $(\mathrm{L}-\mathrm{ARG}=8.387$ vs. $\mathrm{M}-\mathrm{ARG}=9.538 \mathrm{~g})$, livers $(\mathrm{L}-\mathrm{ARG}=33.87 \mathrm{vs} . \mathrm{M}-\mathrm{ARG}=41.07 \mathrm{~g})$, spleens $(\mathrm{L}-$ $\mathrm{ARG}=1.07$ vs. $\mathrm{M}-\mathrm{ARG}=1.42 \mathrm{~g})$, lungs $(\mathrm{L}-\mathrm{ARG}=17.00$ vs. $\mathrm{M}-\mathrm{ARG}=19.90 \mathrm{~g}$ ) and kidneys $(\mathrm{L}-\mathrm{ARG}=9.66$ vs. $\mathrm{M}$-ARG $=12.00 \mathrm{~g})$. On the other hand, L-piglets compared with M-piglets born from sows fed the ARG had higher relative brain weights $(\mathrm{L}-\mathrm{ARG}=2.80$ vs. $\mathrm{M}$-ARG $=2.25)$ and a higher brain:liver weight ratio (L-ARG = 1.14 vs. $\mathrm{M}-\mathrm{ARG}=0.90)(\mathrm{DIET} \times \mathrm{BtW}$ interaction; $P<$ $0.001)$. No such differentiation was observed between LCtrl vs. M-Ctrl. It is also noteworthy that the absolute brain weight did not differ between L-ARG (33.5 g) and M-ARG (33.8 g). Together, these results suggest that besides the obvious positive association between $\mathrm{BtW}$ of piglet and organ size, an early gestational ARG supplementation has slightly greater effect on organ development of offspring with intermediate compared with low BtW. Finally, males and females differed $(P$ $<0.05)$ in absolute weights of liver (34.18 vs. 36.73 $\mathrm{g})$, lung weight (18.80 vs. $17.82 \mathrm{~g})$ and relative heart weight $(0.69$ vs. $0.66 \mathrm{~g} / 100 \mathrm{~g} \mathrm{BtW})$.

\section{Myofiber characteristics of the Semitendinosus muscle}

Except for the greater $(P=0.078)$ area of the $\mathrm{STM}_{\mathrm{d}}$ in OL compared with IN offspring, the extent of IUC did not affect total muscle area, muscle area of the $\mathrm{STM}_{1}$ nor $\mathrm{STM}_{\mathrm{d}}$ and $\mathrm{STM}_{1}$ myofiber number of selected offspring (Table 5). By contrast, the areas of the $\mathrm{STM}_{\mathrm{d}}$ and $\mathrm{STM}_{1}$ and, consequently, of the whole STM were larger $(P \leq 0.025)$ in offspring born from ARG sows compared with Ctrl sows. However, regarding the $\mathrm{STM}_{\mathrm{d}}$ area, ARG supplementation had a greater impact on OL compared to IN offspring (IUC $\times$ DIET; $P=0.007$ ). In addition, the STM tended to be larger in M piglets from ARG sows compared with piglets from the other BtW categories $(\mathrm{STM} ; \mathrm{M}-\mathrm{ARG}=8.573 ; \mathrm{L}-\mathrm{ARG}=7.002 ; \mathrm{M}-\mathrm{Ctrl}=$ 6.996; $\mathrm{L}-\mathrm{Ctrl}=6.271 \mu \mathrm{m}^{2} \times 10^{7}$, and $\mathrm{STM}_{\mathrm{l}} ; \mathrm{M}-\mathrm{ARG}=$ 5.494; $\mathrm{L}-\mathrm{ARG}=4.301 ; \mathrm{M}-\mathrm{Ctrl}=4.181 ; \mathrm{L}-\mathrm{Ctrl}=3.875$ $\mu \mathrm{m}^{2} \times 10^{7}$; DIET $\times$ BtW interaction, $\left.P \leq 0.061\right)$. Total myofiber number was $12 \%$ greater $(P=0.003)$ in the ARG group; this is primarily a result of a $13 \%$ greater $(P=0.022)$ TNF of the $\mathrm{STM}_{\mathrm{l}}$. In the $\mathrm{STM}_{\mathrm{d}}$, where differentiation between $\mathrm{P}$ and $\mathrm{S}$ myofibers was possible, the number of $\mathrm{S}$ myofibers, but not $\mathrm{P}$ myofibers, was numerically $(P=0.124)$ greater in piglets of ARG sows. As a consequence, the S:P myofiber ratio tended $(P=0.051)$ to be greater in the $\mathrm{STM}_{\mathrm{d}}$ of these piglets. While L- and Mpiglets did not differ with respect to total muscle area and TNF of the whole STM, BtW had an effect $(P<0.05)$ on TNF in the $\mathrm{STM}_{\mathrm{d}}(\mathrm{L}=188,925$ vs. $\mathrm{M}=208,792)$, the number of $S$ myofibers $(L=182,927$ vs. $M=202,776)$ and tended to have an effect $(P=0.069)$ on the number of $\mathrm{P}$ myofibers $(L=5,998$ vs. $M=5,986)$ also in the $S_{T} M_{d}$. Due to the lack of an effect of BtW and of a DIET $\times \mathrm{BtW}$ interaction in TNF, the positive effect of ARG supplementation on myofiber hyperplasia was similar for $\mathrm{L}$ and $\mathrm{M}$ piglets ( $L=506,274$ vs. $M=567,783$ myofibers).

\section{Gene expression in the Semitendinosus muscle}

The level of PRKAA2 expression in the STM was greater $(P=0.024)$ in IN compared with OL offspring (Table 6). In addition, ARG appeared to have a greater impact on the expression of this gene in IN than in OL offspring $($ IUC $\times$ DIET; $P=0.034)$. Furthermore, a IUC $\times$ DIET interaction effect $(P=0.013)$ was found in the expression of IGF2; however, Tukey's post hoc comparison did not identify individual differences between means. The expression of MYOD1 tended $(P=0.056)$ to be lower in $\mathrm{L}$ - than $\mathrm{M}$-pigs $(\mathrm{L}=1.96$ vs. $\mathrm{M}=1.86)$, and a tendency $(P=0.091)$ to a DIET $\times \mathrm{BtW}$ interaction effect on PRKAA2 expression was found, where M-piglets from Ctrl sows displayed the lowest expression compared with the remaining piglets $(\mathrm{M}-\mathrm{Ctrl}=0.44 ; \mathrm{L}-\mathrm{Ctrl}=0.53 ; \mathrm{M}$ $\mathrm{ARG}=0.59 ; \mathrm{L}-\mathrm{ARG}=0.60$ relative expression level) . Again, there were no differences in individual interaction means identified by the Tukey's post hoc comparison.

\section{Discussion}

The increased litter size of modern sow breeds is likely associated with increased incidents of IUC and consequently IUGR. Therefore, an increased proportion of underdeveloped piglets within the litters can be observed $[21,22]$. These piglets display a lower postnatal survival rate [23], and a poorer growth performance compared with their larger littermates [24, 25]. These impairments can in part be attributed to the reduced myofiber hyperplasia mainly due to lower formation of $S$ myofibers [8]. One approach to enhance hyperplasia is by supplementing L-arginine to the sows during early gestation, shown to be leading to increased formation of $\mathrm{P}$ myofibers, which serve as a scaffold for the development of the $S$ myofibers [13]. To alter the intra-uterine environment, either unilateral ovary-hysterectomy or unilateral oviduct ligation of sows can be applied, where sows subjected to the latter procedure have shown to display minimal crowding and adequate placental development 
Table 5 Myofiber characteristics in the Semitendinosus muscle of selected offspring born from oviduct ligated (OL; non crowded) and intact (IN; relatively crowded) sows fed an unsupplemented (Ctrl) or L-arginine supplemented diet (ARG) from d 14 to 28 of gestation

\begin{tabular}{|c|c|c|c|c|c|c|c|c|c|c|}
\hline \multirow[b]{2}{*}{ Item } & \multicolumn{2}{|l|}{ IN } & \multicolumn{2}{|l|}{$\mathrm{OL}$} & \multirow[b]{2}{*}{ SEM } & \multirow[b]{2}{*}{ IUC } & \multicolumn{3}{|c|}{$P$-value ${ }^{2}$} & \multirow[b]{2}{*}{ DIET×BtW } \\
\hline & Ctrl & ARG & Ctrl & ARG & & & DIET & BtW & IUCXDIET & \\
\hline Observations & 19 & 19 & 17 & 15 & & & & & & \\
\hline \multicolumn{11}{|l|}{ Muscle area, $\mu \mathrm{m}^{2} \times 10^{7}$} \\
\hline Total & 5.762 & 6.780 & 7.505 & 8.795 & 0.9429 & 0.144 & 0.003 & 0.653 & 0.738 & 0.053 \\
\hline Dark portion & $2.359^{x}$ & $2.278^{x}$ & $2.772^{\mathrm{ax}}$ & $3.572^{\text {by }}$ & 0.2931 & 0.078 & 0.025 & 0.233 & 0.007 & 0.573 \\
\hline Light portion & 3.151 & 4.118 & 4.906 & 5.677 & 0.8279 & 0.143 & 0.011 & 0.910 & 0.786 & 0.061 \\
\hline \multicolumn{11}{|l|}{ Myofiber number, $\mathrm{N}$} \\
\hline Total muscle & 476,025 & 527,711 & 536,451 & 607,928 & $35,511.0$ & 0.236 & 0.003 & 0.136 & 0.604 & 0.475 \\
\hline \multicolumn{11}{|l|}{ Dark portion } \\
\hline Total myofibers & 193,928 & 198,254 & 184,590 & 218,604 & $22,898.2$ & 0.884 & 0.131 & 0.002 & 0.231 & 0.560 \\
\hline Primary myofibers $(P)$ & 6,105 & 5,840 & 5,868 & 6,156 & 638.8 & 0.970 & 0.974 & 0.069 & 0.422 & 0.575 \\
\hline Secondary myofibers (S) & 187,823 & 192,414 & 178,722 & 212,448 & $22,455.9$ & 0.883 & 0.124 & 0.002 & 0.231 & 0.559 \\
\hline S:P ratio ${ }^{3}$ & 30.8 & 33.2 & 30.6 & 34.4 & 2.86 & 0.912 & 0.051 & 0.356 & 0.643 & 0.337 \\
\hline Light portion & 282,097 & 329,457 & 351,860 & 389,324 & $32,639.6$ & 0.234 & 0.022 & 0.889 & 0.778 & 0.236 \\
\hline
\end{tabular}

[18]. Thus, compared with intact natural crowded sows as used in the current study, OL sows with average prolificacy are suitable models for investigating the consequences of IUC and IUGR in newborn piglets. Hence, intact prolific sows with naturally crowded uterus and OL sows with a "non-crowded uterus" were used in the present study to mimic two degrees of IUC and to investigate whether the positive effect of early gestational supplementation of the sows with L-arginine on myofiber hyperplasia observed in 75-day-old fetuses [13] would continue until birth and would differ depending on the extent of IUC.

Table 6 Relative expression of myogenesis-related genes in the Semitendinosus muscle of selected offspring born from oviduct ligated (OL; non crowded) and intact (IN; relatively crowded) sows fed an unsupplemented (Ctrl) or L-arginine supplemented $\operatorname{diet}(A R G)$ from d 14 to 28 of gestation'

\begin{tabular}{|c|c|c|c|c|c|c|c|c|c|c|}
\hline \multirow[b]{2}{*}{ Gene $^{3}$} & \multicolumn{2}{|l|}{ IN } & \multicolumn{2}{|l|}{$\mathrm{OL}$} & \multirow[b]{2}{*}{ SEM } & \multicolumn{5}{|c|}{$P$-value ${ }^{2}$} \\
\hline & $\overline{\mathrm{Ctrl}}$ & ARG & $\overline{\mathrm{Ctrl}}$ & ARG & & IUC & DIET & BtW & IUCXDIET & DIET $\times B+W$ \\
\hline Observations & 16 & 17 & 17 & 15 & & & & & & \\
\hline IGF2 & 2.36 & 1.55 & 0.91 & 1.70 & 0.555 & 0.487 & 0.967 & 0.965 & 0.013 & 0.950 \\
\hline IGFBP5 & 5.63 & 5.65 & 2.32 & 4.62 & 2.190 & 0.489 & 0.233 & 0.275 & 0.290 & 0.297 \\
\hline MSTN $^{4}$ & 1.60 & 1.64 & 0.46 & 0.98 & 1.754 & 0.351 & 0.232 & 0.105 & 0.241 & 0.110 \\
\hline MYF5 $^{4}$ & 0.35 & 0.42 & 0.24 & 0.28 & 1.694 & 0.631 & 0.531 & 0.895 & 0.974 & 0.159 \\
\hline MYF6 & 0.58 & 0.65 & 1.18 & 0.98 & 0.576 & 0.623 & 0.859 & 0.893 & 0.664 & 0.631 \\
\hline$M Y O D 1^{4}$ & 2.36 & 1.84 & 0.68 & 0.48 & 2.143 & 0.223 & 0.340 & 0.056 & 0.885 & 0.418 \\
\hline MYOG & 0.94 & 0.70 & 1.32 & 1.11 & 0.255 & 0.333 & 0.168 & 0.392 & 0.915 & 0.417 \\
\hline PRKAA2 & $0.72^{x}$ & $1.04^{\text {by }}$ & $0.26^{x}$ & $0.15^{\mathrm{ax}}$ & 0.194 & 0.024 & 0.264 & 0.298 & 0.034 & 0.091 \\
\hline
\end{tabular}

${ }^{1}$ Results are presented as least squares means of interactions between the two main factors extent of intra uterine crowding and dietary treatment and pooled SEM ${ }^{2}$ Probability values for the effects of extent of intra uterine crowding (IUC), dietary treatment (DIET), birth weight (BtW), and interactions IUC $\times$ DIET and DIET $\times$ BtW ${ }^{3}$ IGF2 Insulin-like growth factor 2, IGFBP5 Insulin-like growth factor binding protein 5, MSTN Myostatin, MYF5 myogenic factor 5, MYF6 myogenic factor 6, MYOD1 Myogenic differentiation 1, MYOG Myogenin (myogenic factor 4), PRKAA2 Protein kinase AMP-activated, alpha 2 catalytic subunit

${ }^{4}$ Statistical evaluation was performed with log transformed data

a,bWithin a row for the main factor treatment, least squares means without a common superscript differ $(P<0.05)$

${ }^{x, y}$ Within a row for the main factor treatment, least squares means without a common superscript differ $(0.05<P<0.10)$ 


\section{Sow performance and litter characteristics}

Important causes of IUGR are impaired placental development, including suboptimal vascularization of the placenta, increased numbers of fetuses due to high prolificacy and uneven distribution of energy and dietary nutrients among the fetuses [26]. As indicated by the number of total and born alive piglets in combination with the corresponding BtW, IUGR occurred to a greater extent in IN sows compared with OL sows. A sow with a litter size of $\geq 15$ is categorized as being high prolific [24, 27]. This was the case with the IN sows. On the contrary, OL sows had a litter size below the average herd level (9.7 vs. 12.3 live born). The OL sows compared with the IN sows gave birth to a smaller number of stillborn piglets, which was expected from previous findings associating increased litter size with a greater number of stillborn piglets [27]. Litter characteristics of IN sows were in agreement with results from a previous study where offspring developing in a crowded compared with an uncrowded intra-uterine environment exhibited phenotypes associated with IUGR [18]. In the present study, performance of OL sows with respect to litter size and average BtW was comparable to that observed in low to average prolific sows [22].

Effects of maternal dietary L-arginine supplementation on offspring have been previously investigated, but both dietary level, onset of supplementation during gestation and impact on sow and offspring traits have varied greatly among different studies as reviewed by $\mathrm{Wu}$ et al. [28]. Among reported effects of L-arginine are increased numbers of total born, born alive and total litter BtW in multiparous sows [29]. However, the sows included in the two former studies had an average litter size of 13 to 14 piglets, thus are to be categorized as average rather than highly prolific sows with no expected major impact of IUC and IUGR. In the present study, dietary supplementation of L-arginine did not significantly affect the sow reproductive performance. Nevertheless, numerical improvements of particularly the number of piglets born alive as well as a greater BtW of offspring in IN-ARG compared with IN-Ctrl sows were observed. However, the reproduction data must be interpreted with caution due to the low number of sows used in this study.

\section{Muscle and organ weights of offspring}

The greater BtW and weight of STM and PM of offspring from OL sows compared with IN sows were foreseen as it has been reviewed extensively that there is a high correlation between large litter size and extent of crowding as well as greater within-litter variation of BtW and greater number of low BtW offspring [2, 30, 31]. Organ weights of offspring were within the normal range of newborn piglets $[18,32]$. The tendency for an increased absolute STM weight in offspring from ARG sows suggests that, independent of IUC, L-arginine supplementation promotes muscle development of offspring, an observation that has to the best of the authors' knowledge not been shown in previous studies.

Besides reduced $\mathrm{BtW}$, brain:liver weight ratio has been shown to positively correlate with uterine crowding [11] and therefore is an indicator of IUGR [33]. The brainsparing mechanism ensures steady relative brain weight development when maternal nutrient supply does not match requirements for adequate fetal development [34]. The greater liver weight combined with the similar brain weight resulted in a lower brain:liver weight ratio in offspring from ARG sows compared with Ctrl sows and supports the hypothesis that L-arginine supplementation has the potential to alleviate the negative impact of IUGR. In addition, the absolute heart weight was only numerically greater in ARG compared with Ctrl, an observation that has also been related to low birth weight pigs at slaughter age [35]. Thus, with the exception of the brain:liver ratio, this observation would not support the positive effect of L-arginine on organ development under crowding conditions.

Due to the rather high level and intake of crude protein and supplementation of daily L-arginine, a great load of maternal arginine could be expected. However, as discussed above, no detrimental effects on either the sow or the offspring traits were observed, indicating extensive catabolism of arginine and that maternal intake of arginine was not excessive [36]. Thus, it was concluded that the level of supplemented arginine was within the safety margin eliciting no toxicity or adverse effects [37, 38], whereas higher crude protein level and arginine concentration of the diet might lead to impaired reproductive performance, antagonism between amino acids and toxicity of ammonia to sows and their fetuses [28].

\section{Myofiber-related traits of the Semitendinosus muscle}

It is widely accepted that the formation of S myofibers is highly dependent on fetal nutrient uptake [12]. Thus, a reduced nutrient availability in the placenta during mid to late gestation, is likely to result in a lower $\mathrm{S}$ myofiber hyperplasia. Previous studies showed that a lower number of myofibers was associated with reduced muscle mass at weaning and at slaughter age $[6,39]$ meaning an ongoing disadvantage during the entire fattening performance. In the present study, supplementing Larginine to the sows during early gestation resulted in an increased TNF, with the greatest contribution derived from the second wave of myofiber formation as indicated by the greater S:P ratio in the $\mathrm{STM}_{\mathrm{d}}$ and the greater TNF in the $\mathrm{STM}_{1}$. In comparison, a similar previous study reported that early gestational supplementation with L-arginine enhanced prenatal hyperplasia, but, 
in contrast, the main increase of TNF originated from the formation of $\mathrm{P}$ myofibers [13]. However, in that study myofiber hyperplasia was assessed at $\mathrm{d} 75$ of gestation, a time point where hyperplasia of $\mathrm{S}$ myofibers is still ongoing. It is worth mentioning that the increased hyperplasia observed in offspring from ARG sows was independent of BtW (L-ARG: 529,186 vs. M-ARG: $606,453 ; P=0.136)$. This finding contradicts our hypothesis that underprivileged fetuses would preferentially benefit from ARG supplementation by an increased placental vascularization. Results of a recent study [40] suggested that supplementing the gestational diet with either L-arginine, ractopamine, or a combination of the two increased myofiber diameter, indicating that supplementation had an effect on muscle fiber hypertrophy rather than hyperplasia. Ultimately, this resulted in a lower proportion of low BtW piglets $(<0.8-1.2 \mathrm{~kg} \mathrm{BtW})$, and an increased proportion of medium and high $\mathrm{BtW}$ piglets $(>1.2-1.6 \mathrm{~kg} \mathrm{BtW})$ from L-arginine supplemented compared with unsupplemented sows [40]. However, interestingly and in contrast to the present study, a lower TNF was observed in offspring from supplemented compared with unsupplemented sows. One explanation for the discrepancy between the observation in our study and the study of Garbossa et al. [40] could be the mode of L-arginine supplementation, either during $\mathrm{d}$ 14-28 or 25-53 of gestation, respectively, and at either $0.89 \%$ or $1.00 \%$ of the diet, respectively. With these combined results in mind, it is relevant to reflect on the extent to which supplementary L-arginine is directing dietary energy for hyperplasia or hypertrophy in fetuses during the different phases of gestation. Furthermore, investigating the impact of gestational supplementation on hyperplasia especially in post-weaning pigs would be of great importance, as results on this matter are contradictory. For instance, supplementing L-carnitine daily to L-BtW piglets during the suckling period resulted in a third wave of hyperplasia [41] during the nursing period, but no difference in TNF was found between control and L-carnitine supplemented pigs at the age of slaughter [42]. Based on this contradiction, one could speculate that changes occurring during the prenatal period are more manifested and less prone to environmental changes in the postnatal period, thus, having permanent positive effects until the animal reaches slaughter weight.

In light of this discussion and based on earlier findings $[43,44]$, one can assume that maternal arginine concentration was increased in plasma of sows fed L-arginine during the gestational period from d 14-28.

\section{Gene expression of myogenesis-related genes in the Semitendinosus muscle}

Muscle development during the perinatal period requires the regulation of several myogenesis related genes
[45]. In the present study none of the genes analyzed were responding to the extent of IUC or dietary treatment, except for PRKAA2, the expression of which was up-regulated in the STM of IN offspring compared with OL offspring. PRKAA2 is a known inhibitor of muscle protein synthesis [46], and its greater expression in IN offspring is consistent with their lower $\mathrm{BtW}$ and relative STM weight emphasizing the importance of this gene in pre-natal muscle development. In contrast to the increased TNF at birth elicited by maternal L-arginine supplementation, results from the gene expression analysis did not support a myogenic effect at the molecular level. As hyperplasia ceases around d 90 of gestation, genes involved in myogenesis including myofiber formation might no longer show a specific up-regulation, but would rather be expressed at a steady state at birth when the STM was sampled. However, although there was no direct effect of L-arginine supplementation on the gene expression of myogenesis-related genes, it appears that IGF2 and PRKAA2 expressions in neonate STM could be influenced by the dietary level of this particular amino acid in certain uterine environments because there was a significant interaction.

\section{Conclusion}

In conclusion, the present study further adds to the increasing evidence that intra-uterine crowding prevalent in high prolific sows critically affects the phenotype of the offspring. This was manifested by the low $\mathrm{BtW}$ in contrast to the moderate litter size and offspring BtW of the OL counterparts. Confirming our first hypothesis, $\mathrm{L}$-arginine in the early gestational diet seems to reduce the negative impacts of IUGR, as shown by the increased hyperplasia, body weight and STM area of the offspring at birth. As muscle area increased more than TNF, L-arginine supplementation obviously not only enhanced prenatal myofiber hyperplasia but also hypertrophy. However, details concerning the way in which L-arginine affects myofiber development on cellular and molecular levels remain to be determined. The second hypothesis that L-arginine would be especially efficient in L-BtW piglets was not confirmed. Still, this feeding strategy could be of great benefit to especially L-BtW pigs as they are particularly vulnerable. Thus, L-arginine supplementation to sows in early gestation would potentially improve the survival rate during nursery, and the growth potential during fattening of L-BtW piglets.

\footnotetext{
Abbreviations

ARG: Arginine supplementation; BtW: Birth weight; Ctrl: Alanine supplementation; DIET: Dietary treatment; IGF2: Insulin-like growth factor 2; IGFBP5: Insulin-like growth factor binding protein 5; IN: Intact sows; IUC: Intra-uterine crowding; IUGR: Intra-uterine growth retardation; L: Low; M: Intermediate; MSTN: Myostatin; MYF5: Myogenic factor 5; MYF6: Myogenic factor 6; MYOD1: Myogenic differentiation 1; MYOG: Myogenin (myogenic factor 4); OL: Unilateral oviduct ligated; P: Primary; PM: Psoas major;
} 
PRKAA2: Protein kinase AMP-activated alpha 2 catalytic subunit; RPL4 (LOC100038029): Ribosomal protein L4; S: Secondary; SD: Standard deviation; STM: Semitendinosus muscle; STM $_{d}$ : Semitendinosus muscle dark portion; STM: Semitendinosus muscle light portion; TBP: TATA box binding protein TNF, total number of myofibers

\section{Acknowledgements}

The authors would like to thank Guy Maikoff and his staff for their excellent work in the piggery, and Dr. Paolo Silacci and his staff for their valuable support with our laboratory work.

\section{Funding}

No external funding was used for this study.

\section{Availability of data and materials}

The datasets supporting the conclusions of this article are included within the article.

\section{Authors' contributions}

JGM analyzed and interpreted, CP performed the experimental work at slaughter and muscle histology, MK was a major contributor in reviewing the manuscript, GB had the idea for the experiment, planned and supervised the experiment and was a major contributor in writing the manuscript. All authors read and approved the final manuscript.

\section{Competing interests}

The authors declare that they have no competing interests.

\section{Consent for publication}

Not applicable.

\section{Ethics approval and consent to participate}

Experimental protocols were complied with and approved by The Cantonal Committee for Animal Care (approval no. FR14/10). The experiment was conducted at Agroscope (Posieux, Switzerland).

\section{Author details}

${ }^{1}$ Agroscope Posieux, la tioleyre 4, 1725 Posieux, Switzerland. ${ }^{2}$ ETH Zurich, Institute of Agricultural Sciences, Universitätsstrasse 2, 8092 Zurich, Switzerland.

Received: 30 November 2016 Accepted: 6 June 2017

Published online: 01 July 2017

\section{References}

1. Tuchscherer M, Puppe B, Tuchscherer A, Tiemann U. Early identification of neonates at risk: Traits of newborn piglets with respect to survival. Theriogenology. 2000;54(3):371-88. doi:10.1016/S0093-691X(00)00355-1.

2. Foxcroft GR, Bee G, Dixon W, Hahn M, Harding J, Patterson J, et al. Consequences of selection for litter size on piglet development. In: Wiseman J, Varley MA, McOrist S, Kemp B, editors. Paradigms in Pig Science. Nottingham: Nottingham Univ. Press; 2007. p. 207-29.

3. Rekiel A, Wiecek J, Batorska M, Kulisiewicz J. Effect of sow prolificacy and nutrition on preand postnatal growth of progeny - a review. Ann. Anim. Sci. 2014;14(1):3-15. doi:10.2478/aoas-2013-0060.

4. Bérard J, Pardo CE, Bethaz S, Kreuzer M, Bee G. Intra-uterine crowding decreases average birth weight and affects muscle fiber hyperplasia in piglets. J Anim Sci. 2010;88:3242-50. doi:10.2527/jas.2010-2867.

5. Dwyer CM, Fletcher JM, Stickland NC. Muscle cellularity and postnatal growth in the pig. J Anim Sci. 1993;71(12):3339-43. doi:10.2527/1993.71123339x.

6. Nissen PM, Jorgensen PF, Oksbjerg N. Within-litter variation in muscle fiber characteristics, pig performance, and meat quality traits. J Anim Sci. 2004; 82(2):414-21. doi:10.2527/2004.822414x

7. Rehfeldt C, Kuhn G. Consequences of birth weight for postnatal growth performance and carcass quality in pigs as related to myogenesis. J Anim Sci. 2006;84(Suppl):E113-23. doi:10.2527/2006.8413_supplE113x.

8. Swatland HJ. Muscle growth in the fetal and neonatal pig. J Anim Sci. 1973; 37(2):536-45. doi:10.2527/jas1973.372536x

9. Ashmore CR, Addis PB, Doerr L. Development of muscle fibers in the fetal pig. J Anim Sci. 1973;36(6):1088-93. doi:10.2527/jas1973.3661088x.
10. Beermann DH, Cassens RG, Hausman GJ. A second look at fiber type differentiation in porcine skeletal muscle. J Anim Sci. 1978;46(1):125-32. doi:10.2527/jas1978.461125x

11. Town SC, Putman CT, Turchinsky NJ, Dixon WT, Foxcroft GR. Number of conceptuses in utero affects porcine fetal muscle development. Reproduction. 2004;128(4):443-54. doi:10.1530/rep.1.00069.

12. Wigmore PM, Stickland NC. Muscle development in large and small pig fetuses. J Anat. 1983;137(Pt 2):235-45.

13. Bérard J, Bee G. Effects of dietary L-arginine supplementation to gilts during early gestation on foetal survival, growth and myofiber formation. Animal. 2010;10:1680-7. doi:10.1017/S1751731110000881.

14. Li X, Bazer FW, Johnson GA, Burghardt RC, Erikson DW, Frank JW, et al. Dietary supplementation with $0.8 \%$ L-arginine between days 0 and 25 of gestation reduces litter size in gilts. J Nutr. 2010;140(6):1111-6. doi:10.3945/ jn.110.121350.

15. Wu GY, Morris SM. Arginine metabolism: nitric oxide and beyond. Biochem. J. 1998;336:1-17. doi:10.1042/bj3360001.

16. Reynolds LP, Redmer DA. Utero-placental vascular development and placental function. J Anim Sci. 1995;73(6):1839-51. doi:10.2527/1995.7361839.

17. Hazeleger W, Ramaekers R, Smits C, Kemp B. Effect of Progenos on placenta and fetal development in pigs. J Anim Sci. 2007;85:98.

18. Pardo CE, Bérard J, Kreuzer M, Bee G. Intrauterine crowding in pigs impairs formation and growth of secondary myofibers. Animal. 2013;7(3):430-8. doi: 10.1017/S1751731112001802

19. Livak KJ, Schmittgen TD. Analysis of relative gene expression data using real-time quantitative PCR and the 2(-Delta Delta C(T)) Method. Methods. 2001;25(4):402-8. doi:10.1006/meth.2001.1262.

20. Hellemans J, Mortier G, De Paepe A, Speleman F, Vandesompele J. qBase relative quantification framework and software for management and automated analysis of real-time quantitative PCR data. Genome Biol. 2007; 8(2):R19. doi:10.1186/gb-2007-8-2-r19.

21. Hermesch S, Luxford BG, Graser HU. Genetic parameters for lean meat yield, meat quality, reproduction and feed efficiency traits for Australian pigs: 3 . Genetic parameters for reproduction traits and genetic correlations with production, carcase and meat quality traits. Livest Prod Sci. 2000;65(3):26170. doi:10.1016/S0301-6226(00)00151-2.

22. Quesnel H, Brossard L, Valancogne A, Quiniou N. Influence of some sow characteristics on within-litter variation of piglet birth weight. Animal. 2008; 2(12):1842-9. doi:10.1017/S175173110800308X.

23. Roehe R, Kalm E. Estimation of genetic and environmental risk factors associated with pre-weaning mortality in piglets using generalized linear mixed models. Anim. Sci. 2000;70:227-40. doi:10.1017/S1357729800054692.

24. Quiniou N, Dagorn J, Gaudré D. Variation of piglets' birth weight and consequences on subsequent performance. Livest Prod Sci. 2002;78(1):6370. doi:10.1016/S0301-6226(02)00181-1.

25. Beaulieu AD, Aalhus JL, Williams NH, Patience JF. Impact of piglet birth weight, birth order, and litter size on subsequent growth performance, carcass quality, muscle composition, and eating quality of pork. J Anim Sci. 2010;88(8):2767-78. doi:10.2527/jas.2009-2222.

26. Wootton R, McFadyen IR, Cooper JE. Measurement of placental blood flow in the pig and its relation to placental and fetal weight. Biol Neonate. 1977; 31(5-6):333-9. doi:10.1159/000240984.

27. Foxcroft GR, Dixon WT, Dyck MK, Novak S, Harding JC, Almeida FC. Prenatal programming of postnatal development in the pig. Soc Reprod Fertil Suppl. 2009:66:213-31.

28. Wu GY, Bazer FW, Satterfield MC, Li XL, Wang XQ, Johnson GA, et al. Impacts of arginine nutrition on embryonic and fetal development in mammals. Amino Acids. 2013;45(2):241-56. doi:10.1007/s00726-013-1515-Z.

29. Gao K, Jiang Z, Lin Y, Zheng C, Zhou G, Chen F, et al. Dietary Larginine supplementation enhances placental growth and reproductive performance in sows. Amino Acids. 2012;42(6):2207-14. doi:10.1007/ s00726-011-0960-9.

30. Foxcroft GR, Town SC. Prenatal programming of postnatal performance the unseen cause of variance. Advances in Pork Production. 2004:15:269.

31. Wu G, Bazer FW, Wallace JM, Spencer TE. Board-invited review: Intrauterine growth retardation: Implications for the animal sciences. J Anim Sci. 2006; 84(9):2316-37. doi:10.2527/jas.2006-156.

32. Pardo CE, Mueller S, Bérard J, Kreuzer M, Bee G. Importance of average litter weight and individual birth weight for performance, organ and myofiber characteristics of progeny. Livest Sci. 2013:157:330-8. doi:10.1016/j.livsci. 2013.06.015. 
33. Town SC, Patterson JL, Pereira CZ, Gourley G, Foxcroft GR. Embryonic and fetal development in a commercial dam-line genotype. Anim. Reprod. Sci. 2005;85(3-4):301-16. doi:10.1016/j.anireprosci.2004.05.019.

34. DeLong GR. Effects of nutrition on brain development in humans. Am J Clin Nutr. 1993;57(2):286S-90S.

35. Rehfeldt C, Tuchscherer A, Hartung M, Kuhn G. A second look at the influence of birth weight on carcass and meat quality in pigs. Meat Sci. 2008;78(3):170-5. doi:10.1016/j.meatsci.2007.05.029.

36. Hou Y, Yao K, Yin Y, Wu G. Endogenous Synthesis of Amino Acids Limits Growth, Lactation, and Reproduction in Animals. Advances in Nutrition: An International Review Journal. 2016;7(2):331-42. doi:10.3845/an.115.010850.

37. Wu G, Bazer FW, Cudd TA, Jobgen WS, Kim SW, Lassala A, et al.

Pharmacokinetics and safety of arginine supplementation in animals. J Nutr. 2007;137(6):1673S-1680.

38. Wu Z, Hou Y, Hu S, Bazer FW, Meininger CJ, McNeal CJ, et al. Catabolism and safety of supplemental l-arginine in animals. Amino acids. 2016:1-12. doi:10.1007/s00726-016-2245-9.

39. Rehfeldt C, Lang IS, Gors S, Hennig U, Kalbe C, Stabenow B, et al. Limited and excess dietary protein during gestation affects growth and compositional traits in gilts and impairs offspring fetal growth. J Anim Sci. 2011;89(2):329-41. doi:10.2527/jas.2010-2970.

40. Garbossa CA, Junior FM, Silveira H, Faria PB, Schinckel AP, Abreu ML, et al. Effects of ractopamine and arginine dietary supplementation for sows on growth performance and carcass quality of their progenies. J Anim Sci. 2015;93(6):2872-84. doi:10.2527/jas.2014-8824.

41. Lösel D, Kalbe C, Rehfeldt C. L-Carnitine supplementation during suckling intensifies the early postnatal skeletal myofiber formation in piglets of low birth weight. J Anim Sci. 2009;87(7):2216-26. doi:10.2527/jas.2008-1662.

42. Lösel D, Rehfeldt C. Effects of L-carnitine supplementation to suckling piglets on carcass and meat quality at market age. Animal. 2013;7(7):1191-8. doi:10.1017/S1751731113000268

43. Mateo RD, Wu G, Bazer FW, Park JC, Shinzato I, Kim SW. Dietary L-arginine supplementation enhances the reproductive performance of gilts. J Nutr. 2007;137(3):652-6.

44. Li X, Bazer FW, Johnson GA, Burghardt RC, Frank JW, Dai Z, et al. Dietary supplementation with $\mathrm{L}$-arginine between days 14 and 25 of gestation enhances embryonic development and survival in gilts. Amino Acids. 2014; 46(2):375-84. doi:10.1007/s00726-013-1626-6.

45. Pas MFW, Wit AAW, Priem J, Cagnazzo M, Davoli R, Russo V, et al. Transcriptome Expression Profiles in Prenatal Pigs in Relation to Myogenesis. J Muscle Res Cell Motil. 2005;26(2):157-65. doi:10.1007/s10974-005-7004-6.

46. Bolster DR, Crozier SJ, Kimball SR, Jefferson LS. AMP-activated Protein Kinase Suppresses Protein Synthesis in Rat Skeletal Muscle through Downregulated Mammalian Target of Rapamycin (mTOR) Signaling. J Biol Chem. 2002;277(27):23977-80. doi:10.1074/jbc.C200171200.

47. Foxcroft GR, Dixon WT, Novak S, Putman CT, Town SC, Vinsky MDA. The biological basis for prenatal programming of postnatal performance in pigs. J Anim Sci. 2006;84(E. Suppl):E105-12. doi:10.2527/2006.8413_supplE105x.

\section{Submit your next manuscript to BioMed Central and we will help you at every step:}

- We accept pre-submission inquiries

- Our selector tool helps you to find the most relevant journal

- We provide round the clock customer support

- Convenient online submission

- Thorough peer review

- Inclusion in PubMed and all major indexing services

- Maximum visibility for your research

Submit your manuscript at www.biomedcentral.com/submit

) Biomed Central 